\title{
Exploring the Disruptiveness of Cryptocurrencies: A Causal Layered Analysis-Based Approach
}

\author{
Matti Mäntymäki ${ }^{1(\bowtie)}$, Milla Wirén ${ }^{1}$, and A. K. M. Najmul Islam ${ }^{2}$ \\ 1 Turku School of Economics, Turku, Finland \\ \{matti.mantymaki,milla.wiren\}@utu.fi \\ 2 Department of Future Technologies, University of Turku, \\ 20014 Turku, Finland \\ najmul.islam@utu.fi
}

\begin{abstract}
The purpose of this study is to explore whether the diffusion of cryptocurrencies represents a disruptive change and what is the potential magnitude of this change. To this end, we take disruptive innovation theory as our point of departure to scrutinize cryptocurrencies as an instance of sociotechnical change. We employ Causal Layered Analysis to develop our four-layer analytical framework to conceptually examine the changes pertained by the diffusion of cryptocurrencies. We provide examples of changes company-level, industry-level as well as societal changes where cryptocurrencies have played a central role. On a company level, cryptocurrencies provide a cost-efficient means for cross-border money transfer and thus pose a significant threat to the existing intermediary-based business models. On an industry level, many central banks are experimenting with crypto- or digital currencies. On a societal level, cryptocurrencies play an important role in particularly when the traditional institutions and societal structures collapse. For example, in Venezuela's recent political and economic crisis, cryptocurrencies contributed to the development of a parallel financial system when the bolivar practically lost its value. Our study provides an analytical framework to systematically evaluate the potential disruptive nature of cryptocurrencies as well as other blockchain-based technologies.
\end{abstract}

Keywords: Blockchain - Cryptocurrencies · Disruption · Disruptive innovation $\cdot$ Causal Layered Analysis

\section{Introduction}

Since the inception of Bitcoin in 2009 [1], thousands of cryptocurrencies (also known as Altcoin) have emerged that use the blockchain technology [2, 3]. Five most valuable cryptocurrencies, Bitcoin, Etherum, XRP, Bitcoin Cash, and EOS have a total market cap of more than 200 billion USD ${ }^{1}$. The rapid development of blockchain or distributed ledger technologies has paved way for various Financial Technology (FinTech)

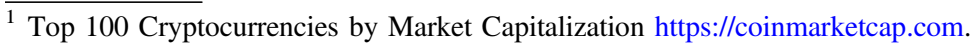

(C) IFIP International Federation for Information Processing 2020

Published by Springer Nature Switzerland AG 2020

M. Hattingh et al. (Eds.): I3E 2020, LNCS 12066, pp. 27-38, 2020.

https://doi.org/10.1007/978-3-030-44999-5_3
} 
innovations. Alongside venture capitalists and FinTech startups, major banks and stock exchanges have rolled out blockchain-based products and services. Furthermore, according to Barontini and Holden [4] several central banks have established explorative as well as experimental blockchain-based initiatives as a part of the prospect for central bank-issued crypto- or digital currencies.

All in all, there is vivid debate among practitioners and academics if, or to what extent, applications of blockchain such as cryptocurrencies will have a disruptive impact on the global financial sector, central banks, or the dominant role of traditional currencies [5-10]. At the same time, however, it is largely unclear what qualifies a change to be disruptive [11-13], i.e. how to conceptually and theoretically distinguish between disruptive and more evolutionary change.

As a result, the research question this study addresses is two-fold: (1) does the diffusion of cryptocurrencies represent a disruptive change, and (2) what is the potential magnitude of this change? To this end, we build on disruptive innovation theory [1417] to scrutinize cryptocurrencies as an instance of socio-technical change [18-22] and conceptually explore its disruptiveness through the Causal Layered Analysis [23-26].

With this paper, we make two main contributions: first we use our CLA-based analytical framework to discuss and conceptually scrutinize the disruptive potential of cryptocurrencies. Second, we discuss and present a conceptual distinction between normal and disruptive change that potentially allows identifying disruptive potential ex ante.

The paper proceeds as follows: in the second section we discuss the concept of disruptive change. Thereafter we present and discuss the CLA as a method for analyzing ongoing socio-technical change. The fourth section focuses on cryptocurrencies. In the fifth section we discuss the disruptiveness of cryptocurrencies through our CLAbased analytical framework. The sixth and final section concludes the paper.

\section{Disruptive Change}

The concept of disruption entered the management literature from innovation studies, as Christensen was puzzled about why do successful companies sometimes fail seemingly overnight [15]. The resulting answer sketched the overview of what has since become known as disruptive innovation theory. In brief, the theory posits that: (i) incumbents ignore the arrival of innovations that enter the market from niche position (originally from the low-end), (ii) incumbents overshoot their offering aims leaving room for simpler and easier offerings, and (iii) incumbents invest in sustaining innovations that fit their existing profitability, but ignore investing in potential new openings that would require new, sometimes even cannibalizing business models to become profitable [12, 16, 17, 27, 28].

Reflecting the lack of conceptual clarity surrounding what is disruptive and what type of change qualifies as disruption, Kilkki et al. [11] define disruption as "An agent is disrupted when the agent must redesign its strategy to survive a change in the environment. From the perspective of the system, disruption is an event in which a substantial share of agents belonging to the system is disrupted" (p. 276). In the realm of digital disruption, Skog et al. [29] dig deeper: they define digital disruption as 
"The rapidly unfolding processes through which digital innovation comes to fundamentally alter historically sustainable logics for value creation and capture by unbundling and recombining linkages among resources or generating new ones. Skog et al. further conceptualize digital disruption to pertain three constitutive elements, namely digital innovation, digital ecosystem, and value logics. They define digital innovation as "process of combining digital and physical components to create novel devices, services or business models, bundling them to constitute and enable market offerings, and embedding them in wider sociotechnical environments to enable their diffusion, operation and use" (p. 433). Digital ecosystems in turn are "sociotechnical networks of interdependent digital technologies and associated actors that are related based on a specific context of use" (p. 433). Finally, they define value logics as "foundational rationales for designing, bundling and embedding a digital innovation to fruitfully create and capture value" (p. 434).

The focus of the disruptive innovation theory is on the market events and incumbents. The disruption is identified only ex post, through the wake of destroyed businesses. With respect to scrutinizing the actual disruptive agent, the theory contributes little: in their review of the status quo of the theory, Christensen et al. ended up in '... defining 'disruptiveness' as a relative, not absolute, phenomenon. In other words, a given innovation can be disruptive to one firm but sustaining to another firm" [17, p. 1050].

This relative nature of disruption was taken further by Schuelke-Leech [13], who explored the magnitude of disruption and proposed a two-level approach: the first order disruptions impact localized markets, whereas the second order disruptions emerge as enough of the networked first order disruptions diffuse to impact the whole market. Nevertheless, also this approach is still retrospective and does not directly facilitate anticipatory assessment of disruptive potential. In particular, we argue that disruptive change can pertain changes that take place in more than two levels. To take a multilevel perspective to disruptive change, we employ CLA [23, 24, 26] as the theoretical framework through which to scrutinize the disruptiveness effect of cryptocurrencies.

\section{Causal Layered Analysis of Socio-Technical Change}

\subsection{Causal Layered Analysis}

Previous research in futures studies has explored the possibility of forecasting discontinuities on the macro level [30], the social disruption intertwined with the diffusion of disruptive technological innovations [18], or the possibility of utilizing diverse foresight methods in identifying disruptions [31-33]. Against this backdrop, our approach to distinguishing disruptive change from normal change in the context of cryptocurrencies answers the call for understanding the multi-level nature of disruption [13]. We employ a specific futures research analytical tool, Causal Layered Analysis (CLA), which enables assessing the layered nature of diverse phenomena.

CLA $[23,34]$ is an analytical tool that enables viewing a phenomenon from four different perspectives conceptualized as four analytical levels. Since its introduction, the CLA has been widely adopted as an analytical aid in theorizing and as a useful tool 
in workshop environments, utilized in analyzing complex phenomena in a variety of fields [31, 32, 35-37]. The analytical levels of CLA are traversed up and down to understand the phenomenon on each level in addition to tracing the linkages in between them.

The first analytical level of CLA is litany. It is the imminent appearance of a phenomenon, quantitatively approachable, an issue easy to shape into a headline. For example, "Terrorism is a constant and evolving threat" [36], or "Traffic jams" (adopted from Inayatullah 2003). The litany can also be an entity like United Nations [37], or the election of Donald Trump as the president of the US [38]. While the viewpoints on the issue may differ, the phenomenon on the litany level can be easily recognized. Moreover, on the litany level the changes and solutions are fast and seemingly simple. For example, a litany level solution for traffic jams could be reducing the number of cars.

The second level of CLA is called systemic causes. Systemic causes is also the level of most analytical endeavors. For example, terrorism may be analyzed to result from lack of sufficient threat detection or to be resolved through more widely spread Western democratization [36]. Moreover, on a systemic causes level, traffic jams in turn are caused by improving living standards enabling the ownership of private cars to more individuals, or the flaws in the city planning and road infrastructure [35].

Systemic causes can be approached from several paradigmatic perspectives: positivist, constructivist, critical and utilizing diverse theoretical frameworks from institutional theory to Marxism, actor-network-theory, among others. Compared to the litany level, identifying the systemic causes is more complex. Respectively, the solutions on a systemic are complex and require more time and effort.

The third level in CLA is worldview. The worldview level stems from postmodern approaches to philosophy and sociology [23]. It takes the impact of discourses seriously and zooms into the ideologies, assumptions - to the realm of taken-for-granted that shapes social action [25]. On a worldview level, traffic jams are a consequence of industrialization, which not only mandates the ownership of a car as a symbol of social class, but also dictates work hours, which result in many people being on the streets at the same time. Fundamentally this level explores the mechanisms of meaning, the why of social action. Changes on this level, for example the development of industrial working hours or changes in symbolic value of a private car, are characteristically slow and rarely a result of intentional action [26, 35-38].

The fourth level is called myth/metaphor. The fourth level goes even deeper into meaning, and explores its origins: where do the ideologies and worldviews emerge from? The proposed answer in CLA draws from the primitive reactions, 'gut feelings', shared collective images that are difficult to even shape into conscious explanations.

For example, the myths/metaphors attributed to having a private car can stem from people's innate needs for experiencing autonomy and competence (e.g. Deci and Ryan [39] or claiming a private space [40]. While the changes on the myth/metaphor level changes can be very difficult to identify and conceptualize, the fact that CLA acknowledges the existence of this level may help recognizing and understanding events that unfold on the other three levels of analysis [31, 35-37]. 


\subsection{CLA of Disruptive Change}

To develop our CLA-based framework for distinguishing disruptive change from normal change we take the definition of disruption by Kilkki et al. [11] as our starting point: "An agent is disrupted when the agent must redesign its strategy to survive a change in the environment. From the perspective of a system, disruption is an event in which a substantial share of agents belonging to the system is disrupted" (p. 276). These definitions reveal two essential questions: what needs to happen for an agent to need to "redesign its strategy to survive? What needs to happen for a notable number of agents in a system to need to do the same? While there are other social, economic and environmental issues that may have an impact, here we view the role of technology.

In discussing the emergence of technology-driven social disruption, following Dosi [41], Carlsen et al. [18] note that the concept of technology includes two dimensions: first, the knowledge embedded in a field, like engineering, digital technology or biotechnology, and secondly the technological artefacts solidifying the technological knowhow into material realizations. This provides us with two levels of technological advances: developments in technological artefacts, and advances in the field level technological knowledge.

Dosi [41] elaborates on two additional levels of technological advances. According to Dosi, there are advances that change the paradigm of a given technological field within a given utility and advances that render that whole utility irrelevant through more widespread changes in the needs met with technologies. The examples of the first type of paradigm change include the shift from analogic music recording technologies to digital recordings and the subsequent transformations in distributing music. The second type of paradigm changes consists of major shifts that accompanied for example industrialization; the technologies essential in farming-based societies gave way to technologies necessary in industrial societies.

As a result, we incorporate these insights from the literature to the four levels of CLA to build our analytical framework (Table 1).

Table 1. CLA-based framework of the magnitude of socio-technical change

\begin{tabular}{l|l|l|l}
\hline Level in CLA & $\begin{array}{l}\text { Unit of the } \\
\text { impact of } \\
\text { change }\end{array}$ & Technological objects of change & $\begin{array}{l}\text { Magnitude of } \\
\text { change }\end{array}$ \\
\hline Litany & $\begin{array}{l}\text { Technological } \\
\text { artefacts }\end{array}$ & $\begin{array}{l}\text { New artefacts, incremental innovation, } \\
\text { radical, but bounded innovation }\end{array}$ & Normal change \\
\hline $\begin{array}{l}\text { Systemic } \\
\text { causes }\end{array}$ & $\begin{array}{l}\text { Socio- } \\
\text { technical } \\
\text { systems }\end{array}$ & $\begin{array}{l}\text { Radical innovation that impacts } \\
\text { infrastructures, standards, regulation, } \\
\text { formal institutions }\end{array}$ & $\begin{array}{l}\text { Firm(s) level } \\
\text { disruption }\end{array}$ \\
\hline Worldview & Meaning & $\begin{array}{l}\text { Technological landscape, paradigm level } \\
\text { change within utility, informal institutions } \\
\text { Taken-for-grantedness of paradigm, } \\
\text { change of utility needs }\end{array}$ & $\begin{array}{l}\text { Field/industry } \\
\text { level disruption }\end{array}$ \\
\hline Myth/metaphor & $\begin{array}{l}\text { Origins of } \\
\text { meaning }\end{array}$ & $\begin{array}{l}\text { societal } \\
\text { transformation }\end{array}$ \\
\hline
\end{tabular}


On the level of litany, the technological developments are represented in new technological artefacts resulting from either incremental innovation [15] or such boundedly radical innovations, which primarily replace one artefact with another, without impacting the overall structures or behavior. An example of the latter is for example the launch of the iPhone - while it displaced the then dominant mobile phone providers and shaped the subsequent use of phones, its diffusion built on established infrastructures and already adopted behavior. These technological innovations on the level of artefacts are by themselves not enough for initiating disruption, but merely represent the normal change - even in highly competitive market settings.

When the technological artefacts are radical enough to cause changes on the structures or in the behavior of a notable share of individuals, they have the power of supplanting such individual firms that are reliant on the structures or behavior being changed. Additionally, also the developments within a given field of technology, in the constitution of its knowhow, have a similar impact. These impacts can be represented in changes in the infrastructures, standards and regulations [42]. In short, these changes are systemic level changes and as such have the potential to disrupt a number or firms dependent on the preceding institutional settings.

On the level of worldview, the magnitude of disruption encompasses not only individual firms but industries and whole fields of operation. This requires paradigm level changes within the fields of technological knowledge: the shift from analog to digital era being a notable example $[42,43]$. On this level the technological and social changes are firmly intertwined: the technological affordances drive changes not only in behavior, but also in the informal institutions, and vice versa - the changes in the informal institutions further strengthen the development trajectories of technology.

Finally, on the level of myth/metaphor, the whole of what is taken for granted changes. However, as the changes on this level unfold slowly, driven by the convergence of diverse social, economic, technological and environmental trajectories, the concept of disruption does not apply: the concept of disruption entails a level of surprise, and while we do not here delve the time dimension of disruption, slowly unfolding change, while changing the socio-economic-technological systems profoundly, is incompatible with the current use of the concept.

\section{Cryptocurrencies}

Cryptocurrencies are digital assets that are featured with strong cryptography and can be used as a medium of secure exchange [44]. They allow fast and secured peer-to-peer transactions with minimal processing fees without an intermediary such as a bank. In contrast with the traditional currencies that are controlled by central banks, cryptocurrencies use decentralized technology, especially blockchain [45]. Bitcoin, released in 2009 is the first cryptocurrency that used blockchain to record financial transactions [1]. Bitcoin was developed as a decentralized digital currency to revolutionize the traditional intermediary-based financial industry. Due to the popularity of Bitcoin, many other digital assets similar to Bitcoin were created using blockchain [2]. As of October 2019, Coinmarketcap lists altogether 2354 cryptocurrencies. 
The rate of the creation of cryptocurrencies is defined by the technical system or algorithm and is hence publicly known. In the centralized banking system, central banks control the supply of the currency by printing new money. However, cryptocurrencies have been designed in such a way that the production will decrease by time for some cryptocurrencies. Moreover, a cap is set on the total amount of the currency that would be ever produced for most cryptocurrencies. For example, the cap is 21 million for Bitcoin [46]. Therefore, government, central bank or any other centralized authority cannot decide creating new units of the currency.

Use of cryptocurrencies is permissionless - that is one does not have to ask anyone to use them [3]. Transactions using cryptocurrencies are pseudonymous in nature and so as the accounts or addresses. The cryptocurrency account or address contains nothing but random characters. Thus, it is possible to check the flow of transactions, but connecting them to real world identities is not possible.

The rapid growth and diffusion of cryptocurrencies has created significant economic activity. For example, there is a fast-growing market for investors, as well as opportunities for new businesses such as mining hardware manufactures. The market hype around initial coin offerings (ICO) and tokenization has made cryptocurrencies widely known as a form of crowdfunding ${ }^{2}$.

\section{Disruptiveness of Cryptocurrencies}

When scrutinized through the four levels of change provided by CLA, we can see that cryptocurrencies have challenged traditional currencies in number of ways. Importantly, there are indications that the monopoly of central banks in issuing currencies and controlling the monetary system has been challenged. Table 2 below summarizes the results of our conceptual analysis.

Table 2. Diffusion of cryptocurrencies analyzed through CLA

\begin{tabular}{l|l|l|l}
\hline Level in CLA & $\begin{array}{l}\text { Unit of the } \\
\text { impact of } \\
\text { change }\end{array}$ & Technological objects of change & $\begin{array}{l}\text { Magnitude of } \\
\text { change }\end{array}$ \\
\hline Litany & $\begin{array}{l}\text { Technological } \\
\text { artefacts }\end{array}$ & $\begin{array}{l}\text { Rapid increase in the number of cryptocurrencies } \\
\text { Explosion of peer-to-peer transactions } \\
\text { Market hype around Bitcoin }\end{array}$ & Normal change \\
\hline $\begin{array}{l}\text { Systemic } \\
\text { causes }\end{array}$ & $\begin{array}{l}\text { Socio- } \\
\text { technical } \\
\text { systems }\end{array}$ & $\begin{array}{l}\text { Incumbent financial institutions experimenting with } \\
\text { and adopting blockchain-based technologies } \\
\text { Emergence of services for cross-border money } \\
\text { transfer, erosion of incumbents' business } \\
\text { Regulation for cryptocurrencies emerging }\end{array}$ & $\begin{array}{l}\text { Firmon } \\
\text { disruption }\end{array}$ \\
\hline
\end{tabular}

(continued)

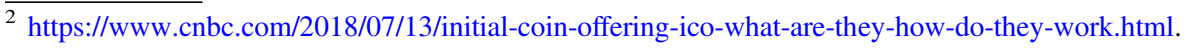


Table 2. (continued)

\begin{tabular}{l|l|l|l}
\hline Level in CLA & $\begin{array}{l}\text { Unit of the } \\
\text { impact of } \\
\text { change }\end{array}$ & Technological objects of change & $\begin{array}{l}\text { Magnitude of } \\
\text { change }\end{array}$ \\
\hline Worldview & Meaning & $\begin{array}{l}\text { Central banks experimenting with their own crypto-/ } \\
\text { digital currencies } \\
\text { Central bank's monopoly in issuing money } \\
\text { challenged and questioned }\end{array}$ & $\begin{array}{l}\text { Fieldindustry } \\
\text { level disruption }\end{array}$ \\
\hline Myth/metaphor & $\begin{array}{l}\text { Origins of } \\
\text { meaning } \\
\text { hyperinflation of the traditional currency (Venezuela) } \\
\text { and establish a parallel economic system } \\
\text { Decentralized technologies enabling new forms or } \\
\text { organizing and agency }\end{array}$ & $\begin{array}{l}\text { Macro-level } \\
\text { societal }\end{array}$ \\
\hline
\end{tabular}

On the level of litany, cryptocurrencies have been gaining popularity for peer-topeer transactions. This has been partially driving by certain actors need to avoid traditional financial institutions since they typically provide information for governmental authorities. In addition, new cryptocurrencies are created at a rapid pace. Investors have been investing in cryptocurrencies with the hope for profits. Taken together, the cryptocurrency market has been constantly evolving since the birth of Bitcoin. As cryptocurrencies promise to remove central authority in the transaction, it can be seen as a threat to banks and other financial institutions, which act as the middlemen in transactions. Therefore, some governments have even banned cryptocurrencies. For example, ICOs were banned in many countries despite their popularity. Even trading cryptocurrencies is illegal in many countries such as $\mathrm{China}^{3}$.

On the level of systemic changes, the growth of cryptocurrencies have started to challenge established companies or organizations. For example, in international money transfer, cryptocurrencies enable very cost-efficient peer-to-peer transactions and thus has the potential to decrease transaction costs by eliminating, or cutting the fees of established middlemen facilitating transactions.

Second, blockchain technologies such as cryptocurrencies typically record the transactions in a distributed ledger which cannot be changed. Therefore, it ensures trust and security without a need for a middleman involved in the transaction. Due to the anonymous nature of cryptocurrencies, it is easier for example to avoid taxation when one uses cryptocurrencies for transactions. Therefore, regulatory bodies interfered to regulate cryptocurrencies in the past years [47]. Blockchain, the underlying technology behind the cryptocurrencies has gained popularity in many other areas such as healthcare and supply-chain [48, 49]. Therefore, it has already become evident that cryptocurrencies have the potential for firm level disruption.

With respect to the worldview level of CLA, we argue that the changes associated with cryptocurrencies represent what CLA considers worldview level. This argument is supported by the fact that banks, central banks, and other financial institutions have

\footnotetext{
${ }^{3}$ https://www.coindesk.com/south-korea-will-maintain-ico-ban-after-finding-token-projects-brokerules.
} 
been looking for possibilities to use private or consortium blockchain as well as offering their own crypto- or digital currencies due to the possible disruption caused by cryptocurrencies.

Lastly, there is some signs that cryptocurrencies can contribute to macro-level societal changes that CLA classifies to represent the myth/metaphor level. The changes at this level are driven by the convergence of diverse social, economic, technological, and environmental trajectories. For example, cryptocurrencies, particularly Dash and Bitcoin have played a role in the recent economic and political turmoil in Venezuela. For example, due to the hyperinflation, price of one cup of coffee increased 373,233\% in just 12 months. As a result, people have increasingly turned to the digital assets cryptocurrencies $^{4}$. Many people converted their bolivars to Bitcoin or other cryptocurrencies to preserve their financial assets. Moreover, salaries have been increasingly paid in cryptocurrencies instead of bolivars. In fact, amidst the crisis, the Venezuelan government also launched its own cryptocurrency, the petro, believed to be backed by oil in order to fight the economic crisis. Taken together, the adoption of cryptocurrencies in Venezuela has skyrocketed and is seen as a way to fight the economic crisis due to the hyperinflation that collapse the value of the bolivar.

Furthermore, the emergence of blockchain technology and cryptocurrencies can be viewed as examples of the emergence of decentralized forms of organizing and thus an alternative to centralized control and authority (cf. [50]).

\section{Discussion and Conclusion}

This study was set out to explore (i) whether the diffusion of cryptocurrencies represents a disruptive change, and (ii) what is the potential magnitude of this change? To meet this objective, we built on disruptive innovation theory [15, 17] (Christensen 1997; Christensen et al. 2018) to scrutinize cryptocurrencies as an instance of sociotechnical change [13, 20-22] and employed Causal Layered Analysis [23, 26] to conceptually examine its disruptiveness.

Our contribution is twofold. First, we contribute to the evolving blockchain and cryptocurrency literature (e.g. [2, 10]; b) by evaluating the disruptive potential of cryptocurrencies with our four-layer analytical framework. In particular, our approach can be used to more systematically analyze the potential and impact of blockchainbased applications and services. As a result, we specifically contribute to the debate whether blockchain-based technologies ability to disrupt existing business models.

Second, we contributed to the disruptive innovation and disruptive change literature (e.g. [17] by using CLA as the foundation of our analytical framework, we describe the potential disruptiveness of an innovation using four layers. This provides a more detailed description of disruptiveness than the dominant two-level approach [13].

The study has a number of limitations that need to be acknowledged. At the same time, we view these limitations as immediate avenues for future research. First, this study is conceptual in nature. Therefore, future research could collect empirical

\footnotetext{
$\overline{{ }^{4} \text { https://www.bbc.com/news/business-47553048. }}$
} 
evidence to verify the applicability of CLA approach in the context of cryptocurrencies. Second, we focused only on one specific use case of blockchain technology and instance of potential disruptive change, i.e. cryptocurrencies. Thus, future research could test the applicability of our CLA-based analytical framework in other applications of blockchain technology as well as entirely different contextual domains - also within the field on information systems studies.

\section{References}

1. Nakamoto, S.: Bitcoin: a peer-to-peer electronic cash system (2008)

2. Islam, A.K.M.N., Mäntymäki, M., Turunen, M.: Why do blockchains split? An actornetwork perspective on Bitcoin splits. Technol. Forecast. Soc. Change 148, 119743 (2019)

3. Islam, N., Mäntymäki, M., Turunen, M.: Understanding the role of actor heterogeneity in blockchain splits: an actor-network perspective of bitcoin forks. In: Proceedings of the 52nd Hawaii International Conference on System Sciences (2019)

4. Barontini, C., Holden, H.: Proceeding with Caution-A Survey on Central Bank Digital Currency. BIS Paper, no. 101, 8 January 2019

5. Caliskan, K.: Data Money: The Socio-Technical Infrastructure of Cryptocurrency Blockchains (2018). SSRN 3372015

6. Dodd, N.: The social life of Bitcoin. Theory Cult. Soc. 35(3), 35-56 (2018)

7. Iansiti, M., Lakhani, K.R.: The truth about blockchain. Harv. Bus. Rev. 95(1), 118-127 (2017)

8. Jun, M.: Blockchain government-a next form of infrastructure for the twenty-first century. J. Open Innov. Technol. Mark. Complex. 4(1), 7 (2018)

9. Luther, W.J.: Cryptocurrencies, network effects, and switching costs. Contemp. Econ. Policy 34(3), 553-571 (2016)

10. Zook, M.A., Blankenship, J.: New spaces of disruption? The failures of Bitcoin and the rhetorical power of algorithmic governance. Geoforum 96, 248-255 (2018)

11. Kilkki, K., Mäntylä, M., Karhu, K., Hämmäinen, H., Ailisto, H.: A disruption framework. Technol. Forecast. Soc. Change 129, 275-284 (2018)

12. Petzold, N., Landinez, L., Baaken, T.: Disruptive innovation from a process view: a systematic literature review. Creat. Innov. Manag 28(2), 157-174 (2019)

13. Schuelke-Leech, B.-A.: A model for understanding the orders of magnitude of disruptive technologies. Technol. Forecast. Soc. Change 129, 261-274 (2018)

14. Baiyere, A.: Discovering the Role of Information Technology In Disruptive InnovationsEnabler, Sustainer or Barrier (2016)

15. Christensen, C.M.: The Innovator's Dilemma. Harvard Business School Press, Cambridge (1997)

16. Christensen, C.M.: The ongoing process of building a theory of disruption. J. Prod. Innov. Manag. 23(1), 39-55 (2006)

17. Christensen, C.M., McDonald, R., Altman, E.J., Palmer, J.E.: Disruptive innovation: an intellectual history and directions for future research. J. Manag. Stud. 55(7), 1043-1078 (2018)

18. Carlsen, H., Dreborg, K.H., Godman, M., Hansson, S.O., Johansson, L., Wikman-Svahn, P.: Assessing socially disruptive technological change. Technol. Soc. 32(3), 209-218 (2010)

19. Hayes, A.: The socio-technological lives of bitcoin. Theory Cult. Soc. 36(4), 49-72 (2019). https://doi.org/10.1177/0263276419826218 
20. McLeod, L., Doolin, B.: Information systems development as situated socio-technical change: a process approach. Eur. J. Inf. Syst. 21(2), 176-191 (2012)

21. Sovacool, B.K., Hess, D.J.: Ordering theories: typologies and conceptual frameworks for sociotechnical change. Soc. Stud. Sci. 47(5), 703-750 (2017)

22. Lyytinen, K., Newman, M.: Explaining information systems change: a punctuated sociotechnical change model. Eur. J. Inf. Syst. 17(6), 589-613 (2008)

23. Inayatullah, S.: Causal layered analysis: poststructuralism as method. Futures 30(8), 815829 (1998)

24. Inayatullah, S.: The Causal Layered Analysis (CLA) Reader. Theory and Case Studies of an Integrative and Transformative Methodology (2004)

25. Milojević, I., Inayatullah, S.: Narrative foresight. Futures 73, 151-162 (2015)

26. Inayatullah, S., Milojevic, I.: CLA 2.0: transformative research in theory and practice (2015)

27. Gans, J.S.: Keep calm and manage disruption. MIT Sloan Manag. Rev. 57(3), 83 (2016)

28. Lucas, H.C., Goh, J.M.: Disruptive technology: how Kodak missed the digital photography revolution. J. Strateg. Inf. Syst. 18(1), 46-55 (2009)

29. Skog, D.A., Wimelius, H., Sandberg, J.: Digital disruption. Bus. Inf. Syst. Eng. 60(5), 431437 (2018)

30. Ayres, R.U.: On forecasting discontinuities. Technol. Forecast. Soc. Change 65(1), 81-97 (2000)

31. Heinonen, S., Minkkinen, M., Karjalainen, J., Inayatullah, S.: Testing transformative energy scenarios through causal layered analysis gaming. Technol. Forecast. Soc. Change 124, 101113 (2017)

32. Minkkinen, M., Heinonen, S., Parkkinen, M.: Drilling and blasting to learn scenario construction: experimenting with causal layered analysis as a disruption of scenario work. World Futur. Rev. 11(2), 110-121 (2018). https://doi.org/10.1177/1946756718774940

33. Wayland, R.: Strategic foresight in a changing world. Foresight 17(5), 444-459 (2015)

34. Inayatullah, S.: Causal Layered Analysis: Theory, Historical Context, and Case Studies, pp. 1-52. Tamkang University Press, Taipei (2004)

35. Inayatullah, S.: Alternative futures of transport. Foresight 5(1), 34-43 (2003)

36. Kenny, N.D.: Terrorism futures: constructing and deconstructing using causal layered analysis. In: Inayatullah, S., Milojevic, I. (ed.) pp. 235-252. Tamkang University Press, Taipei (2015)

37. Ketonen-Oksi, S.: Creating a shared narrative: the use of causal layered analysis to explore value co-creation in a novel service ecosystem. Eur. J. Futures Res. 6(1), 1-12 (2018). https://doi.org/10.1186/s40309-018-0135-y

38. Wirén, M.: Strategizing in the new normal: implications of digitalization for strategizing and uncertainty: philosophical and managerial considerations (2018)

39. Deci, E.L., Ryan, R.M.: The "what" and "why" of goal pursuits: human needs and the selfdetermination of behavior. Psychol. Inq. 11(4), 227-268 (2000)

40. Beirão, G., Cabral, J.A.S.: Understanding attitudes towards public transport and private car: a qualitative study. Transp. Policy 14(6), 478-489 (2007)

41. Dosi, G.: Technological paradigms and technological trajectories: a suggested interpretation of the determinants and directions of technical change. Res. Policy 11(3), 147-162 (1982)

42. Tilson, D., Lyytinen, K., Sorensen, C.: Desperately seeking the infrastructure in IS research: conceptualization of "digital convergence" as co-evolution of social and technical infrastructures. In: 2010 43rd Hawaii International Conference on System Sciences (HICSS), pp. 1-10 (2010)

43. Tilson, D., Lyytinen, K., Sørensen, C.: Research commentary-digital infrastructures: the missing IS research agenda. Inf. Syst. Res. 21(4), 748-759 (2010)

44. Chohan, U.W.: Cryptocurrencies: a brief thematic review (2017) 
45. Bech, M.L., Garratt, R.: Central bank cryptocurrencies. BIS Quarterly Review, September 2017

46. Antonopoulos, A.M.: Mastering Bitcoin: Unlocking Digital Cryptocurrencies. O'Reilly Media, Inc., Sebastopol (2014)

47. DeVries, P.D.: An analysis of cryptocurrency, bitcoin, and the future. Int. J. Bus. Manag. Commer. 1(2), 1-9 (2016)

48. Dolgui, A., Ivanov, D., Potryasaev, S., Sokolov, B., Ivanova, M., Werner, F.: Blockchainoriented dynamic modelling of smart contract design and execution in the supply chain. Int. J. Prod. Res., 1-16 (2019)

49. Siyal, A., Junejo, A., Zawish, M., Ahmed, K., Khalil, A., Soursou, G.: Applications of blockchain technology in medicine and healthcare: challenges and future perspectives. Cryptography 3(1), 3 (2019)

50. Beck, R.: Beyond bitcoin: the rise of blockchain world. Computer (Long. Beach. Calif.) 51(2), 54-58 (2018) 